\title{
Improvement of Fatigue Property in High Strength Aluminum Alloy by Shot Peening
}

\author{
Hussain J.Al-Alkawi ${ }^{1}$, Tag Elsir Hassan ${ }^{2}$, Basil Ahmed Selman, Ali \\ Yousif Khenyab $^{3}$, Mohammed j.Kadhim ${ }^{4}$
}

\begin{abstract}
Shot peening process has both the beneficial and detrimentaleffects; therefore, it is difficult and time-consuming task to determine the optimized process parameters based on the fatiguelife. In this study the fatigue of 7001-T6 high strength aluminum alloy has been investigate before and after a shot peeningis beneficial for a treatment to investigate where a shot peening is beneficial for a component with this combination. The effect of $12 \mathrm{~min}$. shot peening on the fatigue behavior of the material used gave an increase in the fatigue life of up to 2.49 times depending on the applied stress, and a $28.34 \%$ increase in the endurance limit of the material. Cumulative fatigue damage was conducted under low-high and high-low stress amplitude .The fatigue life prolonging factor (FLPF) was calculated for different stress amplitudes and it was found that this parameter is an indicator for prolonging the fatigue life.
\end{abstract}

Keywords: shot peening, fatigue, high strength, aluminum alloy, residual stress.

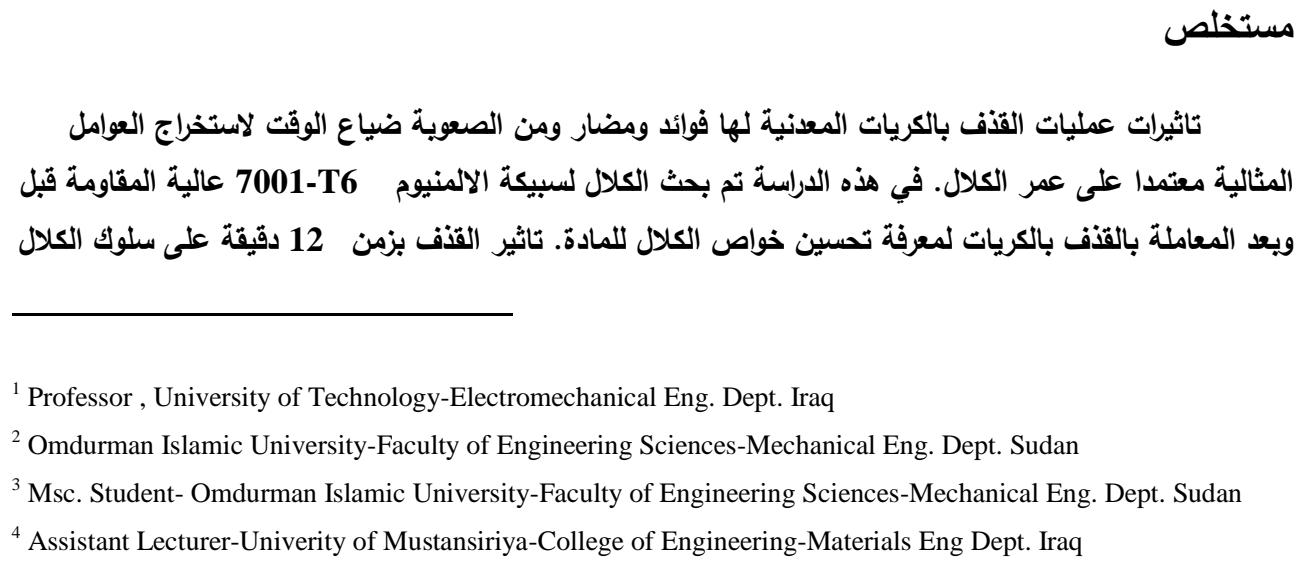




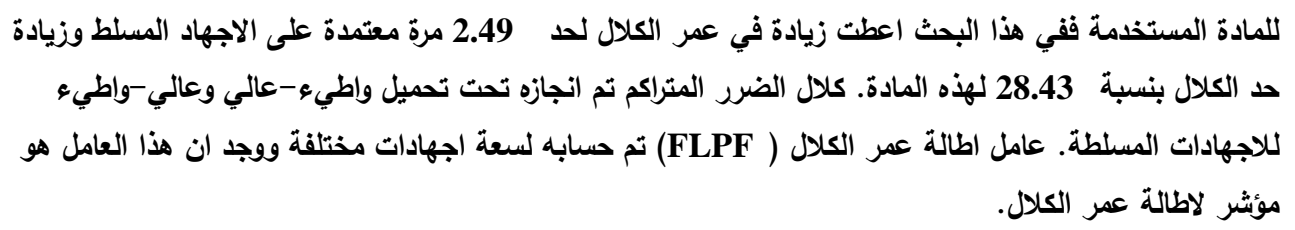

\section{Introduction}

Shot peening is a cold working process widely used to improve the fatigue life of metallic components[1].Several shot peening parameters ,such as shot size , type, velocity, incidence angle, material properties of the target components ..etc have a great influence on the effectiveness of the treatment. Shot peening has both the beneficial and detrimental effects, therefore, it is a difficult and time-consuming task to determine the optimized process parameters based on the fatigue life prolonging factor under the same stress/strain condition and/or fatigue strength improvement percentage under the given fatigue life ,usually for the $1 \times 10^{7}$ cycle [2]. The effect of shot peening on fatigue life extension for 7475-T7351 Al. alloy, reduce small crack growth rates. This beneficial effect is attributed to the compressive residual stresses induced by shot peening in the surface layer [3]. The compressive residual stress field (CRSF) introduced by shot peening was studied comprehensively. The $40 \mathrm{cr}$ steel which is widely applied in industry materials was used and shot peened under different conditions. The maximum of (CRSF) for given material is almost the same even under different shot peening technique, and the surface residual stress value are dependent on both the mechanical properties of target materials and peening parameters[4]. The high cycle fatigue performance of 7075T7451 aluminum alloy was investigated for untreated, laser peened, and 
shot peened conditions under four-point bending at a stress ratio of $\mathrm{R}=0.1$. Results show that laser peening induces a layer of compressive residual stress more than three times deeper than for shot peening and both treatments significantly increase fatigue performance [5].The fatigue life of sand - cast A8magnesium alloy has been investigated before and after a shot peening treatment to investigate whether shot peening is beneficial for a component this combination of relatively low strength and relatively poor initial surface finish. The results show that the fatigue life is significantly improved by the shot peening process [6].

The fatigue strength increased with peening time until $1000 \mathrm{sec}$. above which it remained constant. Shot peening created a nanocrystalline surface layer which improves the fatigue strength of compressive coil springs made from oil tempered wire [7].The depth of compression can be increased by higher intensity peening, realized by increasing the duration of shot bombardment ,peening with larger or higher velocity shot, or both however increased shot peening intensity increase roughness and the level of cold work at the surface, both of which reduce fatigue performance[8].Post-peen polishing can improve surface quality, but material removed by polishing decreases the benefits of shot peening because the layer of compressive stress is typically shallow ,Hence, successful fatigue enhancement from shot peening is a compromise between beneficial compressive residual stresses and detrimental effect on surface quality[9].The objective here is to explore the effect of shot peening on the performance of 7001-T6 aluminum alloy, a material used in fatigue -critical aircraft components. The 7001-T6 alloy is 
commonly selected for aircraft application because of its high strength, high resistance to stress corrosion cracking and good fracture toughness [10].

\section{Material}

Wrough aluminum alloy 7001-T6 was used in this study due to its one of the most versatile, economic and attractive metallic materials. The AA 7001-T6, low-specific weight and high strength to weight ratio and also high electrical and thermal conductance. This alloy is widely used in industry.

Chemical composition of this alloy used in this study is given in table (1) and the mechanical properties are listed in table (2).

Table (1): The Chemical Composition of Aluminum (7001-T6 AL) Alloy, wt\%

\begin{tabular}{|c|c|c|c|c|c|c|}
\hline Elements & $\mathbf{C u}$ & $\mathbf{M g}$ & $\mathbf{Z n}$ & $\mathbf{M n}$ & $\mathbf{S i}$ & Rem. \\
\hline $\begin{array}{c}\text { Standard aluminum } \\
\text { alloy (7001-T6) }\end{array}$ & $1.6-2.6$ & $2.6-3.4$ & $6.8-8.0$ & 0.2 & 0.35 & $\mathrm{Al}$ \\
\hline experimental & 2.01 & 2.8 & 6.95 & 0.206 & 0.34 & $\mathrm{Al}$ \\
\hline
\end{tabular}

Table (2): The Mechanical Properties of Aluminum (7001-T6 AL) Alloy

\begin{tabular}{|c|c|c|c|c|c|}
\hline \multirow[t]{2}{*}{ Property } & $\begin{array}{c}\text { Tensile } \\
\text { strength }\end{array}$ & $\begin{array}{c}\text { Yield } \\
\text { strength }\end{array}$ & \multirow[t]{2}{*}{$\begin{array}{r}\text { Ductility } \\
\text { percent }\end{array}$} & $\begin{array}{c}\text { Endurance } \\
\text { limit }\end{array}$ & $\begin{array}{c}\text { Modulus of } \\
\text { elasticity }\end{array}$ \\
\hline & $\begin{array}{l}(\mathrm{KSi}) \\
(\mathrm{MPa})\end{array}$ & $\begin{array}{l}(\mathrm{KSi}) \\
(\mathrm{MPa})\end{array}$ & & $(\mathrm{MPa})$ & (Gpa) \\
\hline standard & 98676 & $\begin{array}{r}91 \\
627\end{array}$ & 9 & 152 & 73 \\
\hline experimental & $\begin{array}{ll}94 & 649\end{array}$ & $88 \quad 606$ & 10 & 111 & 70 \\
\hline
\end{tabular}




\section{Experimental procedure}

Figure (1) shows the configuration and dimensions of fatigue specimens were machined from $2.1 \mathrm{~mm}$ thick rolled plates with length direction of specimens parallel to longitudinal rolling direction. The final machining is the fine grinding and the surface roughness of machined specimens is $\mathrm{Ra}$ (average roughness) $0.7-1.3 \mu \mathrm{m}$.

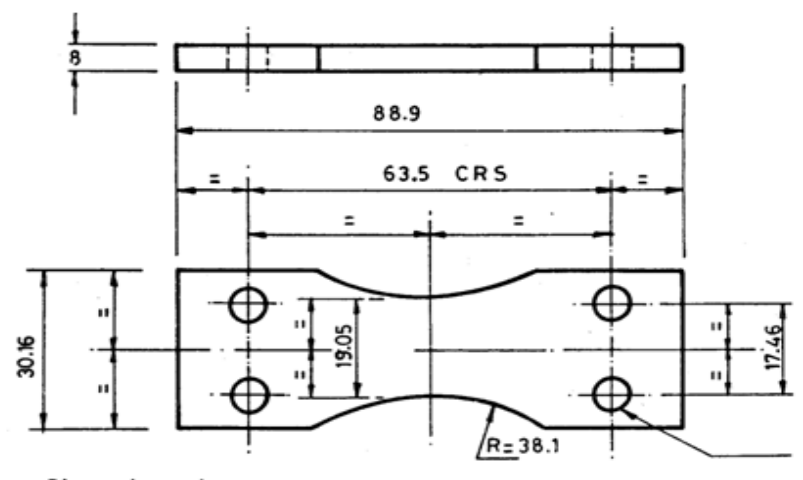

Dimensions in $\mathrm{mm}$

Figure (1): Shows the Dimensions of Fatigue Specimens

Fatigue tests were carried out on reversed-bending machine (Avery Denison LTD) with frequency of $5 \mathrm{HZ}$ at room temperature and stress ratio $\mathrm{R}=-1$. Figure (2) shows the fatigue test.

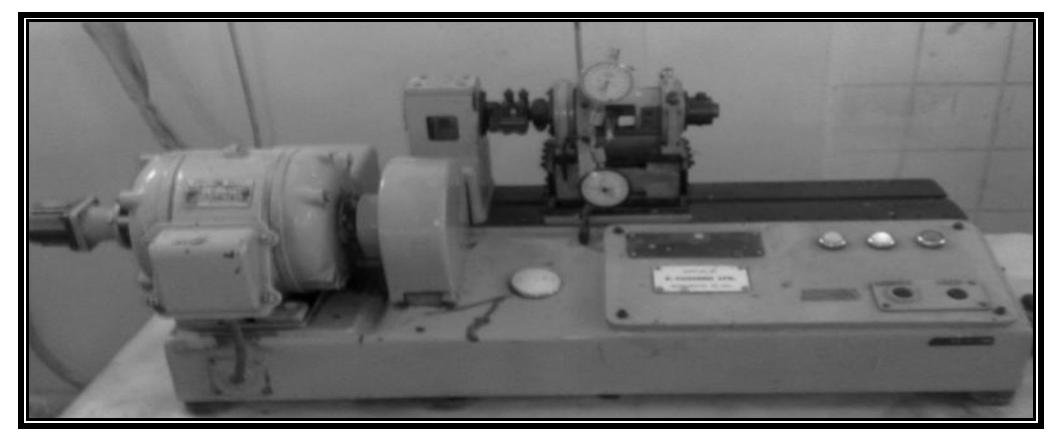

Figure (2): Reversed-Bending Fatigue Test Rig. 
Three groups of specimens were used for fatigue tests. The first group was untreated as machined, tested as the referenced ones. The second groupwas the shot peened ones under 12 min. The third group was the cumulative fatigue tests without and with shot peening at the same time of peening .The peening operation was performed in a special testreg (Shot Tumblast Control Panel model STB-OB).This apparatus enables a defined shot peening treatment on round and flat specimens.

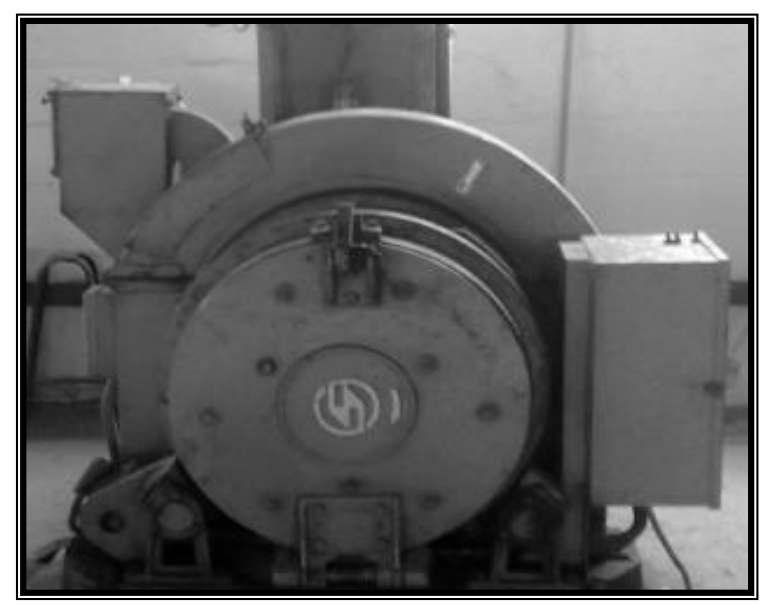

Figure (3): Shot Peening Test Device

The ball material was cast steel with an average ball size of diameter $1 \mathrm{~mm}$ and a Rockwell hardness of 48-50 HRC .The number of balls at the whole operation time was kept constant for a wide range of peening pressure around 12 bars resulting in ball velocities of nearly $40 \mathrm{~m} / \mathrm{s}$. More details can be found elsewhere [9].Figure (3) shows the shot peening device. 


\section{Results and Discussion}

Figure (4) shows the $S-N$ data for the peened and unpeened samples. It can be seen from this figure that shot peened specimens show an increase in fatigue life as compared to the unpeened specimens across the whole range of stress amplitudes, as well as an increase in the endurance fatigue limit.

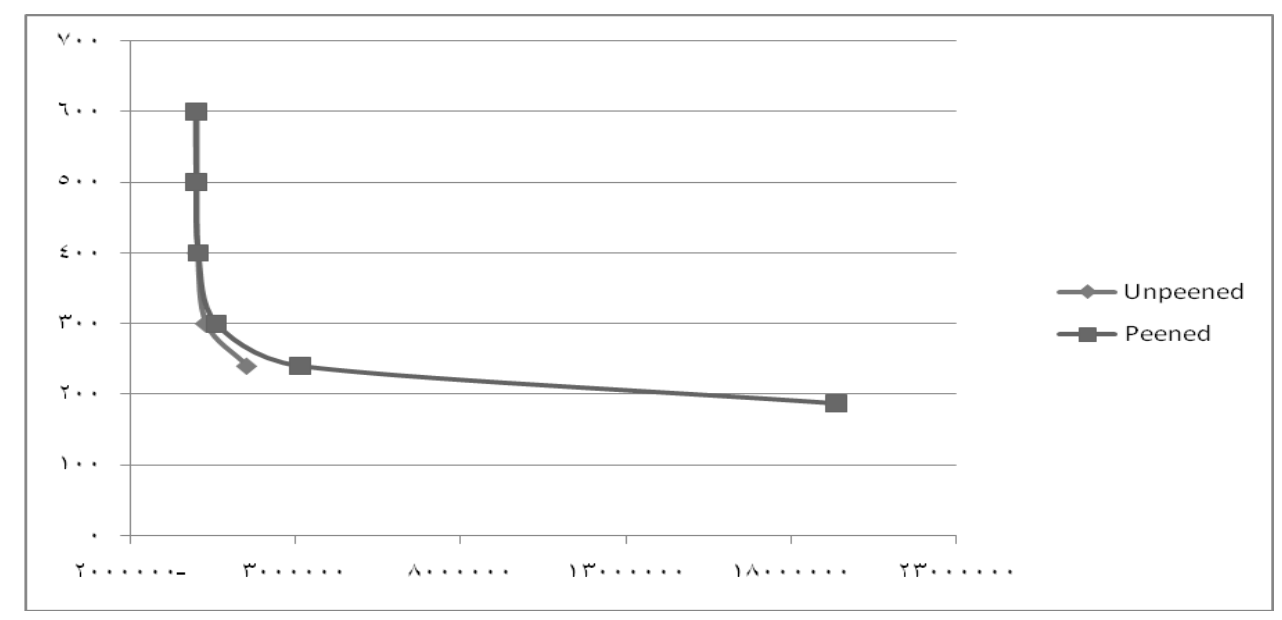

Figure (4): the S-N Curve Behavior of 7001-T6 AL Alloy

The data does show some scatter and the average increase in fatigue life for shot-peened specimens is often greatest at lower stress amplitudes and diminishes at higher stress amplitudes. At higher stresses the residual stress imparted by the peening process are often quickly overcome [11] whilst at lower stresses the peening can give an order of magnitude improvement in resistance to fatigue life .These observations are in good agreement with the findings of Ref. [6]The behavior of the present alloy used can be described under constant loads by the following equations: 
$\sigma_{f}=1620 N_{f}^{-0.134}$ unpeening specimens...

$\sigma_{f}=1893 N_{f}^{-0.138}$ peening specimens

Also figure (4) shows that the improvement in fatigue life is good over the whole stress amplitudes tested in this study. Table (3) gives the improvement factor over a wide range of applied stress.

\section{Roughness Tests}

The performance of controlled shot peening in terms of fatigue it is balance between its beneficial (compressive residual stress and work hardening) and detrimental effects (surface roughness). As shown in table (3). The process of shot peening produces compressive residual stress which in turns increases the surface hardness as result.

SEM examination shows that the surface roughness increases after shot peening.

Table (3): Roughness results under with and without S.P

\begin{tabular}{|c|c|}
\hline SP T $_{\min }$ & Roughness Ra $(\boldsymbol{\mu m})$ of AA 7001-T6 \\
\hline Zero & 0.66 \\
\hline $\mathbf{1 2}$ & 2.124 \\
\hline
\end{tabular}

\section{Microstructure of 7001-T6 Al. Alloy}

The image analysis is results and scanning electron microscope (SEM) photographs taken from the surface of A.A 7001-T6 specimens after and before SP are presented in fig (5). According to this figure shot peening (12 min) increased the surface roughness due to local deformation of surface by 
peening which increase the number of dimples per unit area of the surface. This behavior has been reported in other research and depends on material properties and shot peening time.

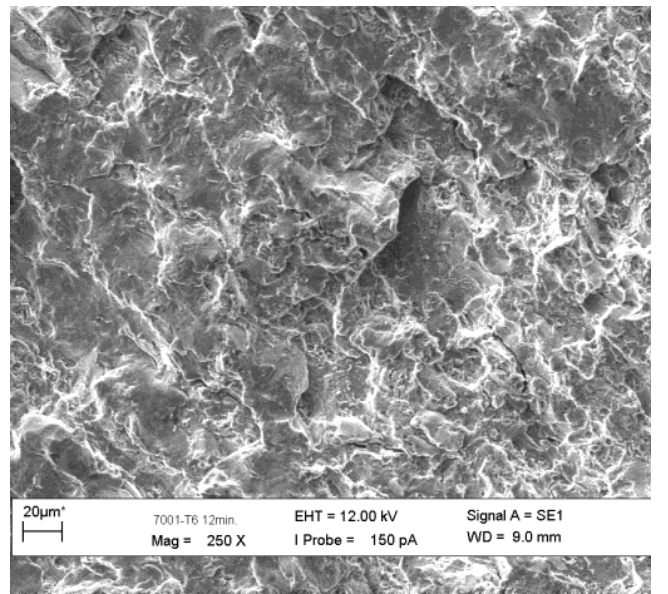

a: before SP

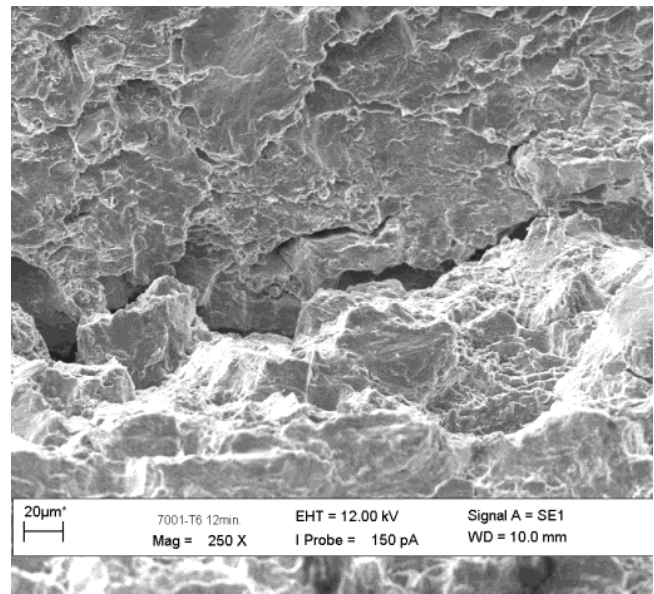

b: after SP

Figure: (5) SEM Image of Surface after and before S.P

\section{Crack Growth}

Development of crack growth after S.P was measured and with crack growth in specimens without SP. Retardation of crack growth was significant particular for cracks shorter than $2 \mathrm{~mm}$. For the specific stress amplitude. Evaluated results enable to estimate threshold of defects, which after the application of the shot penning will be reliably arrested fig (6) shows the fatigue fracture surface. 

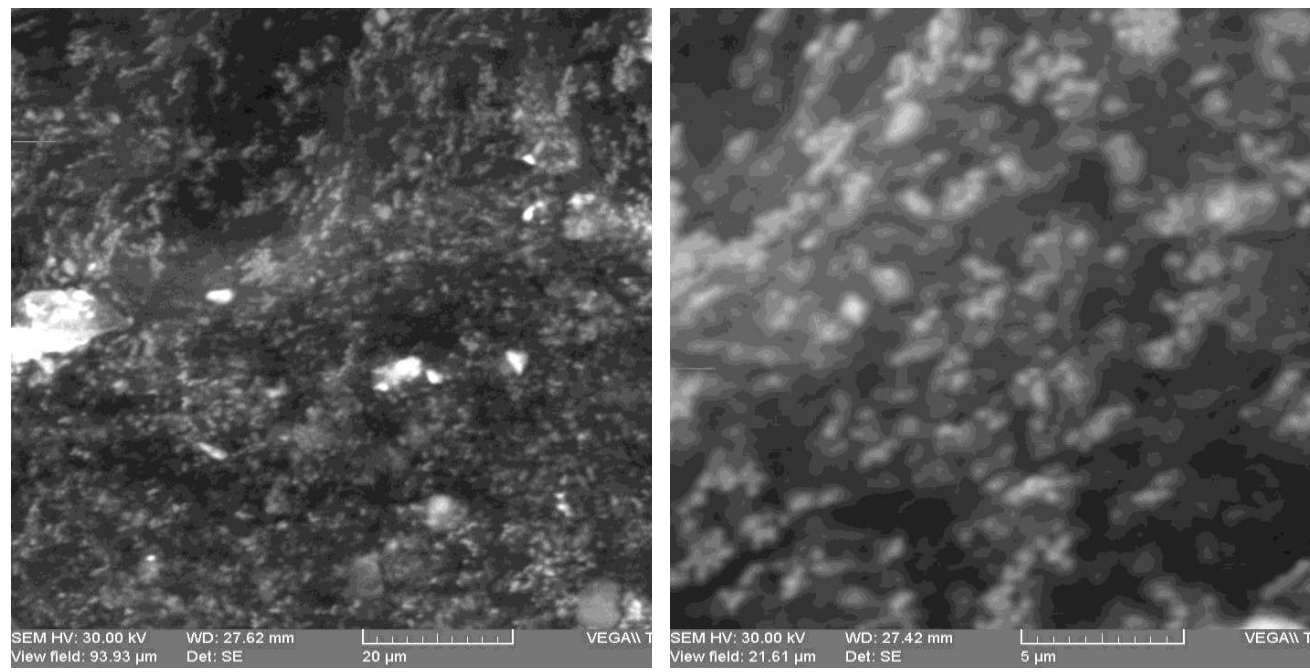

Figure (6) SEM Fractures Surface of AA 7001-T6

Table (4): Improvement Fatigue Life Factor (IFLF).

\begin{tabular}{|c|c|c|c|}
\hline Stress applied (MPa) & $\begin{array}{c}\text { Unpeened life } \\
\text { (cycle) }\end{array}$ & peened life (cycle) & IFLF \\
\hline $\mathbf{1 8 6 . 8 6 *}^{*}$ & $10^{7}$ & 19373356 & 1.937 \\
\hline $\mathbf{2 4 0 * *}$ & 1544664 & 3159080 & 2.045 \\
\hline $\mathbf{3 0 0}$ & 292163 & 627067 & 2.146 \\
\hline $\mathbf{4 0 0}$ & 34138 & 77976 & 2.284 \\
\hline $\mathbf{5 0 0}$ & 6457 & 15478 & 2.397 \\
\hline $\mathbf{6 0 0}$ & 1656 & 4130 & 2.49 \\
\hline
\end{tabular}

*endurance fatigue limit for unpeened specimens at $10^{7}$ cycles.

** endurance fatigue limit for peened specimens at $10^{7}$ cycles.

The variation of IFLF is from 1.937 to $2.49 \mathrm{i}$-e the factor is a round 2.2.barry et.al[4] found that the increase in fatigue life of up to five times 
depending on the applied stress amplitude for cast magnesium A8.Tese increase are significant, and show that the peening treatment may be highly attractive in improving the fatigue life of 7001-T6 Aluminum alloy. There is also an increase in the endurance limit at $10^{7}$ cycles, from $186.86 \mathrm{MPa}$ to $240 \mathrm{MPa}$; an increase of $28.43 \%$ in the available applied stress amplitude.Barry et.al[6] also found that an increase of 30\%in the available applied stress amplitude. An increase in the surface roughness of the specimens was found after peening $(1.8-2.2 \mu \mathrm{m})$ at $12 \mathrm{~min}$. peening but this was not found to be detrimental to the fatigue performance.

\section{Cumulative Fatigue Damage under Shot Peening Ttreatment}

Following the work of Gao [2].To determine the effect of peening on fatigue property, the FLPF (fatigue life prolonging factor) analysis under the same stress or strain conditions is used. The FLPF is calculated as: [2]

$$
F L P F=\frac{N \text { mod fied }- \text { specimen }}{\text { Nbaseline }}-1
$$

Three specimens was taken as a group and made the average fatigue life as the fatigue of the group. For the different low-high and high-low stress amplitudes the fatigue lives of specimens and FLPF are listed in table (5). 
Table (5): Low-high and high-low cumulative fatigue damage lives and FLPF under 12 min. shot peening

\begin{tabular}{|c|c|c|c|c|c|c|c|}
\hline \multicolumn{2}{|c|}{ Unpeened specimen } & \multicolumn{2}{|c|}{ peened specimen } & \multirow{2}{*}{\begin{tabular}{|c|} 
Unpeened \\
$\mathrm{N}_{\mathrm{f}}$ av.
\end{tabular}} & \multirow{2}{*}{$\begin{array}{l}\text { peened } \\
\mathrm{N}_{\mathrm{f}} \text { av. }\end{array}$} & \multirow[b]{2}{*}{ FLPF } & \multirow[b]{2}{*}{ Test program } \\
\hline $\begin{array}{c}\text { Specimen } \\
\text { No. }\end{array}$ & $\mathrm{N}_{\mathrm{f}}$ cycle & $\begin{array}{c}\text { Specimen } \\
\text { No. }\end{array}$ & $\mathrm{N}_{\mathrm{f}}$ cycle & & & & \\
\hline $\mathrm{C1}$ & $1.82 \times 10^{5}$ & $\mathrm{C} 4$ & $4 \times 10^{5}$ & \multirow{3}{*}{$2.373 \times 10^{5}$} & \multirow{3}{*}{$4.633 \times 10^{5}$} & \multirow{3}{*}{0.952} & \multirow{3}{*}{$\begin{array}{l}250 \mathrm{MPa} \\
10^{4}\left\lfloor 10^{4} \text { cycles }\right.\end{array}$} \\
\hline $\mathrm{C2}$ & $2.2 \times 10^{5}$ & $\mathrm{C} 5$ & $3.9 \times 10^{5}$ & & & & \\
\hline $\mathrm{C3}$ & $3.1 \times 10^{5}$ & C6 & $6 \times 10^{5}$ & & & & \\
\hline $\mathrm{C7}$ & $1.1 \times 10^{3}$ & $\mathrm{C} 10$ & $3.2 \times 10^{5}$ & \multirow{3}{*}{$1.266 \times 10^{5}$} & \multirow{3}{*}{$3.74 \times 10^{5}$} & \multirow{3}{*}{1.954} & \\
\hline C8 & $1.8 \times 10^{5}$ & $\mathrm{C} 11$ & $5 \times 10^{3}$ & & & & \multirow{2}{*}{$1 \overline{0^{4}} \backslash 0^{4}$ cycles } \\
\hline $\mathrm{C9}$ & $0.9 \times 10^{3}$ & $\mathrm{C} 12$ & $3.02 \times 10^{5}$ & & & & \\
\hline C13 & $0.88 \times 10^{5}$ & $\mathrm{C} 16$ & $2.08 \times 10^{5}$ & \multirow{3}{*}{$0.876 \times 10^{5}$} & \multirow{3}{*}{$2.4 \times 10^{5}$} & \multirow{3}{*}{1.751} & \multirow{3}{*}{$\begin{array}{l}\overline{350} \stackrel{250 \mathrm{MPa}}{ } \\
\sqrt{6^{4 \text { cycles }}}\end{array}$} \\
\hline $\mathrm{C} 14$ & $0.75 \times 10^{5}$ & $\mathrm{C} 17$ & $2.15 \times 10^{5}$ & & & & \\
\hline $\mathrm{C} 15$ & $1 \times 10^{5}$ & $\mathrm{C} 18$ & $3 \times 10^{5}$ & & & & \\
\hline C19 & $3 \times 10^{4}$ & $\mathrm{C} 22$ & $6.2 \times 10^{5}$ & \multirow{3}{*}{$3.116 \times 10^{5}$} & \multirow{3}{*}{$6.9 \times 10^{4}$} & \multirow{3}{*}{1.214} & \multirow{3}{*}{$\begin{array}{l}400 \quad \\
10^{4} \text { cycles }\end{array}$} \\
\hline $\mathrm{C20}$ & $2.1 \times 10^{4}$ & $\mathrm{C} 23$ & $7.7 \times 10^{5}$ & & & & \\
\hline C21 & $4.25 \times 10^{4}$ & $\mathrm{C} 24$ & $6.8 \times 10^{3}$ & & & & \\
\hline
\end{tabular}

Shot peening under $12 \mathrm{~min}$. improved the cumulative fatigue damage live. It can seen that table (4), the FLPF is more than zero value which indicates significantly improves the fatiguelives under cumulative damage. These results are in good a agreement with the results of Gao [2]. 


\section{Fatigue Strength Improvement Percentage [FSIP]}

The FSIP may be calculated as [2]:

$$
F S I P=\left(\frac{\sigma_{E . L} \text { mod efiedspecimen }}{\sigma_{E . L} \text { baselinespecimen }}-1\right) * 100 \%
$$

For the case study here, the FSIP was determined as $28.43 \%$.this value presents an improvement in fatigue strength at $12 \mathrm{~min}$. shot peening.Gao[2] found a variation in the FSIP value based on the time of peening (2.7\% to $42.2 \%$ for different shot peening time) for 7050-T7451 aluminum alloy.

\section{Conclusions}

1. The effect of shot peening on the fatigue behavior of 7001-T6aluminum alloy has been studied under reversed bending room temperature, stress ratio $\mathrm{R}=-1$ and shot peening time $12 \mathrm{~min}$.

2. A significant improvement in the fatigue life was provided, which an increase in the fatigue life of up to 2.49 times depending on the applied stress.

3. The fatigue strength at $10^{7}$ cycle of 7001-T6 aluminum alloy was increased by shot peening. An increased in fatigue strength was $28.43 \%$ higher than the unpeened fatigue strength at 12 min. shot peening time.

4. The cumulative fatigue peened specimens lives were increased due to 12 min. shot peening i.e the FLPF was more than zero value i.e 0.952 to 1.954. 


\section{References}

[1] H.Y. Miao,D.Demers,S.Larose,C.Perron,MartinLevesque"Experimental study of shot peening and stress peen forming" Journal of materials processing technology 210, 2089-2102(2010).

[2]Y.K.GAO "Improvement of fatigue property in 7050-T77451 aluminum alloy by laser peening and shot peening" material science and engineering A528, 3823-3828 (2011).

[3] Y.K. Gao, X.R. Wu "Expermentalinnvesigation and fatigue life predication for 7475-T7351 aluminum alloy with and without shot peeninginduced residual stress" Beijing institute, 2011.

[4] Yu-KVI GAO, MEI YAO, and JIN-KUILI "An Analysis of Residual stress field, caused by shot peening" METALLURGICAL AND MATERIALS TRANACTION A. 33A, (2002).

[5]Harold Luong, Michael R.Hill"The effects of laser peening and shot peening on high cycle fatigue in 7050-T7451 aluminum alloy"material science and engineering A527,699-707(2010).

[6]N.Barry,S.V.Hainsworth ,M.E.Fitzparrick"effect of shot peening on the fatigue behavior of cast magnesium A8"material science and engineering A507,50-57(2009).

[7]Hideo Mano,SatornKondo,AkihitoMastsumuro " Microstructure surface layer induced by shot peening and its effect on fatigue strength" IEE Explore at 20.5617 UTC from IEE Explore(2011).

[8]P.Peyre,X.Scherpereel,L.Berthe,C.Carbont,R.Fabbro,G.Beranger,C.Lema itre: material science and engineering A280,294-302(2000). 
[9]C.S.Montross,T.Wel.L.Ye,G.Clark,Y.W.Mai,international journal of fatigue 24,1021-1036(2002).

[10]Robert L.Mott"machine elements in mechanical design "Peavrson international edition (2005).

[11] Mohammed FaycalAmer "shot peening effect in partial aircraft aluminum alloy "MSC Thesis University of technology 2002.

[12]U.Martin, I.Altenberger, B.Scholtes, K.Kremmer, et.al, material science and engineering A246, 69-80(1998). 